\title{
Analisis Strategi Pemasaran Jasa Laboratorium Pangan (Studi Kasus pada M-Brio Food Laboratory)
}

\author{
Jono Mintarto Munandar \\ Departemen Manajemen, Fakultas Ekonomi dan Manajemen \\ Institut Pertanian Bogor \\ Email: jonomun@gmail.com \\ Cinde Triatmoko \\ Alumni Departemen Manajemen, Fakultas Ekonomi dan Manajemen \\ Institut Pertanian Bogor \\ Mokhamad Syaefudin Andrianto \\ Departemen Manajemen, Fakultas Ekonomi dan Manajemen \\ Institut Pertanian Bogor \\ Email: syaefudin_andri@yahoo.com
}

\begin{abstract}
The competition is very tight, so M-BRIO Food Laboratory as one of the food testing laboratory requires suitable of marketing strategy. The purpose of this study were (1) Identify and analyze internal and external environmental factors that affect effectivity of the marketing strategy at M-BRIO Food Laboratory, (2) Recommend priorities and appropriate marketing strategies can be applied to the M-BRIO Food Laboratory. Formulation of marketing strategies that go through three stages, (1) the input stage using EFE matrix and IFE matrix,(2) matching stage using the SWOT matrix and,(3) decision stages using paired comparison method for selecting alternative strategies and continued with the analitycal hierarchy process (AHP) method to prioritize marketing strategies appropriate for the company. Internal environmental factors that become the main force is lead by a food expert that has been recognized nationally and internationally. While its main weakness are display of exterior and interior of the laboratory building has not been well-organized and performance of employees who have not been standardized. External environmental factors that can be used as the main opportunity is the development of the technology food testing laboratory. While the main threat for companies is bargaining power of consumers against the company's so high. Priorities recommended marketing strategies are (1) Conduct promotion and education to inform the quality of service, scope of product coverage and the parameters that have been accredited, to food companies, (2) campaign of food safety to the public as a form of promotion and education through food expert as endorser.

Keywords: Marketing Strategy Services, Food Testing Laboratory, Food Testing Services, Food Experts, Food Safety Campaign.
\end{abstract}




\section{Pendahuluan}

Pangan merupakan kebutuhan dasar manusia selain sandang dan papan. Seiring dengan peningkatan jumlah penduduk Indonesia yang cukup signifikan yaitu pada tahun 1995 jumlah penduduk 194.754 .808 jiwa, berkembang menjadi 206.264.595 jiwa (tahun 2000) dan diperkirakan menjadi 237.641 .326 jiwa (tahun 2010) (BPS, 2009), maka permintaan akan kebutuhan bahan pangan semakin meningkat. Seiring dengan permintan kebutuhan pangan, maka hal tersebut berpengaruh terhadap perkembangan industri pangan baik secara kualitas maupun kuantitas. Secara kuantitas, hal ini terbukti dengan bertambahnya jumlah perusahaan makanan dan minuman di Indonesia dari jumlah 4.551 perusahaan tahun 2002, meningkat menjadi 4.722 perusahaan pada tahun 2005 dan 6.063 perusahaan pada tahun 2008 (BPS, 2009).

Pelaku industri pangan harus memperhatikan kualitas jaminan mutu pangan yang diproduksi, karena konsumen semakin cerdas memperhatikan keamanan dan kualitas pangan yang mereka konsumsi. Tuntutan akan kualitas pangan tersebut diatur melalui regulasi yang dibuat oleh pemerintah seperti UU No. 7 Tahun 1996 tentang pangan. Pemerintah melalui Badan Standarisasi Nasional (BSN) telah membuat regulasi dan prosedur berkaitan dengan keamanan pangan melaui penerapan Standar Nasional Indonesia (SNI) pada produk pangan. Pemerintah dalam hal perlindungan konsumen menerapkan regulasi bahwa setiap produk pangan yang akan dipasarkan, harus memenuhi syarat-syarat mutu bahan pangan yang bersangkutan untuk mendapatkan izin perdagangan dari Badan Pengawasan Obat dan Makanan Republik Indonesia (BPOM RI) berupa nomor MD untuk produk yang dijual di dalam negeri dan nomor ML untuk produk yang akan dijual diluar negeri ataupun produk luar yang akan dijual di dalam negeri.

Nomor MD dan ML didapatkan setelah BPOM RI melakukan pengawasan terhadap industri pangan bersangkutan, selain itu untuk mendapatkan izin perdagangan perusahaan yang bersangkutan harus melakukan pengujian produk yang mereka produksi ke laboratorium pengujian pangan yang telah terakreditasi untuk mengetahui mutu dan keamanan pangan dari produk yang akan dipasarkan. Pengujian harus dilakukan oleh laboratorium pengujian pangan yang sudah terakreditasi Komite Akreditasi Nasional (KAN) sebagai laboratorium yang memberikan sertifikasi laporan hasil uji. Selain itu untuk keperluan dokumen ekspor produk pangan dan audit pihak luar diperlukan sertifikat laporan hasil uji dari laboratorium terakreditasi KAN. Hal tersebut memberikan peluang usaha bagi industri jasa laboratorium pengujian pangan di Indonesia.

Permintaan akan jasa analisis pengujian pangan dari masyarakat umum dan khususnya produsen produk pangan, menimbulkan penawaran jasa analisis dari laboratorium pengujian pangan. M-BRIO Food Laboratory merupakan divisi laboratorium di bawah PT. Embrio Biotekindo yang bergerak di bidang pengujian pangan (food specialist) dan telah memperoleh akreditasi dari KAN, dan lembaga sertifikasi Profesi Tenaga Laboratorium Penguji Indonesia. Pada tahun 2010 M-BRIO Food Laboratory memiliki 106 pelanggan yang terdiri dari 55 pelanggan lama dan 51 pelanggan baru. Jumlah pelanggan potensial tersebut merupakan pangsa pasar yang perlu dipertahankan dan dikembangkan. 


\section{Pendapatan Jasa M-BRIO Food Laboratory} Tahun 2010

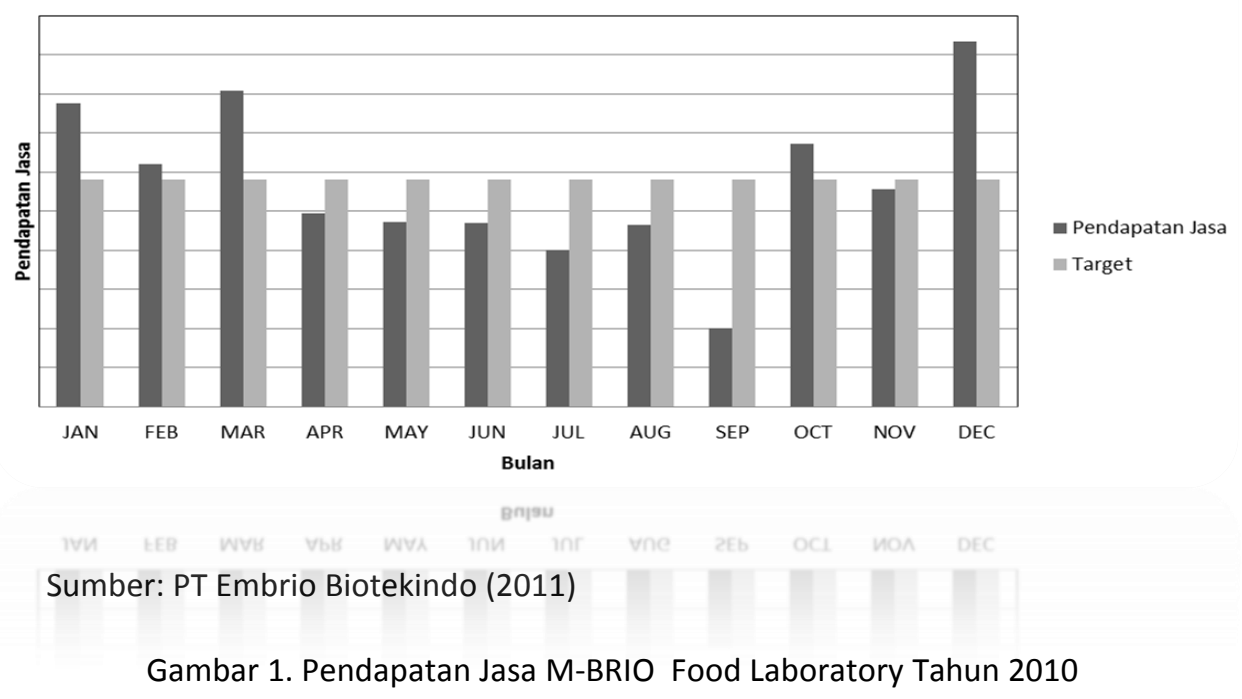

Pada Gambar 1 dapat dilihat bahwa pendapatan jasa pengujian M-BRIO Food Laboratory tahun 2010 pada bulan April, Mei, Juni, Juli Agustus, September dan November belum mencapai target yang ditetapkan oleh manajemen. Sedangkan pada bulan Januari, Pebruari, Maret, Oktober dan Desember sudah mencapai target yang di tentukan. Dari 12 bulan ada 7 bulan yang tidak mencapai target dan hanya 5 bulan yang mencapai target. Agar tujuan perusahaan dapat tercapai, maka manajemen harus memformulasikan strategi pemasaran yang tepat.

Tujuan dari penelitian ini adalah (1) Mengidentifikasi dan menganalisis faktor lingkungan internal dan eksternal yang berpengaruh terhadap strategi pemasaran pada M-BRIO Food Laboratory; (2) Merekomendasikan prioritas alternatif strategi pemasaran yang sesuai pada M-BRIO Food Laboratory.

\section{Metode Penelitian}

Proses manajemen strategi yang lengkap dimulai dari identifikasi misi, tujuan dan strategi perusahaan saat ini, dilanjutkan dengan analisis lingkungan ekternal dan internal, formulasi dan memilih strategi, penerapan strategi dan evaluasi strategi (Umar, 2008). Pada penelitian ini tahapan manajemen strategi dibatasi sampai formulasi dan memprioritaskan strategi. Dari beberapa pendekatan analisis lingkungan dipilih pendekatan fungsional khususnya pemasaran, sesuai dengan tujuan formulasi strategi pemasaran. Analisis lingkungan internal terdiri dari identifikasi kekuatan dan kelemahan perusahaan sedangkan analisis lingkungan eksternal terdiri dari identifikasi peluang dan ancaman. Setelah menganalisis faktor lingkungan internal dan eksternal M-BRIO Food Laboratory, maka dilakukan perumusan strategi yang terdiri dari tiga tahap, yaitu tahap masukan (input stage), tahap pencocokan (matching stage) dan tahap keputusan (decision stage). Dalam tahap masukan digunakan matriks evaluasi faktor internal (internal factor evaluation) - matriks IFE untuk menganalisis kekuatan dan kelemahan internal serta menganalisis ancaman dan peluang eksternal menggunakan matriks evaluasi faktor eksternal (external factor evaluation) - matriks EFE. Selanjutnya dilakukan tahap perumusan strategi dalam matriks strengths 
weaknesses, opportunities, threats (matriks SWOT). Apabila pada tahap keputusan alternatif strategi pemasaran yang dihasilkan cukup banyak, perlu dilakukan pemilihan prioritas. Salah satu cara memilih prioritas adalah dengan metode perbandingan berpasangan (pairwise comparison). Perumusan strategi yang komprehensif dilakukan dengan menggunakan metode AHP (Analytical Hierrachy Process). Kerangka pemikiran penelitian dapat dilihat pada Gambar 2.

Penelitian ini menggunakan data primer dan data sekunder. Data primer diperoleh secara langsung dari wawancara terstruktur dan pengisian kuisioner. Sedangkan untuk data sekunder diperoleh dari studi pustaka, data perusahaan, data dari internet dan literatur-literatur terkait yang mendukung penelitian.

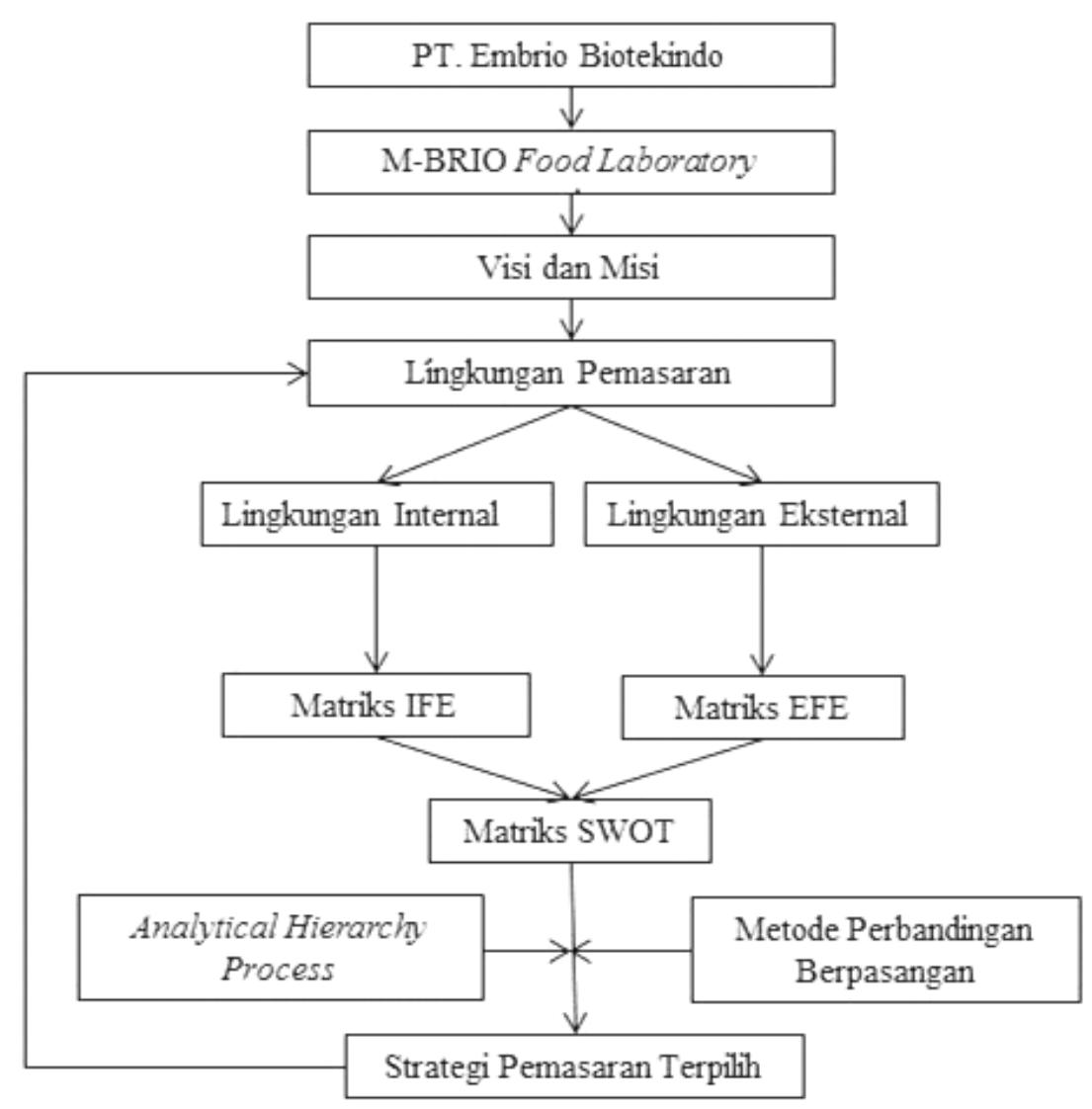

Gambar 2. Kerangka Pemikiran

\section{Hasil Penelitian}

III.1. Identifikasi Kekuatan, Kelemahan, Peluang dan Ancaman M-BRIO Food Laboratory

Hasil identifikasi linkungan internal M-BRIO Food Laboratory terdiri dari kekuatan dan kelemahan. Kekuatan terdiri dari (1) dipimpin oleh pakar pangan yang sudah diakui reputasinya secara nasional dan internasional (Prof. Dr. F.G. Winarno), (2) Memiliki komitmen "Akurat, cepat, dan bersahabat demi kepuasan pelanggan", (3) Laboratorium sudah terakreditasi KAN khusus pangan dengan jasa pengujian melingkupi 56 produk pangan. Kelemahan terdiri dari (1) Sistem administrasi masih manual dan belum memiliki sistem secara terkomputerisasi, (2) Karyawan yang berhubungan langsung dengan pelanggan belum dilatih secara khusus, (3) Penampilan 
karyawan khususnya yang berhubungan dengan pelanggan belum distandarisasi,(4) Eksterior dan interior bangunan laboratorium belum tertata dengan baik,(5) Promosi dan edukasi belum optimal.

Identifikasi lingkungan eksternal M-BRIO Food Laboratory terdiri dari peluang dan ancaman. Peluang terdiri dari (1) Meningkatnya jumlah industri pangan, (2) Perekonomian nasional cenderung stabil, (3) Berkembangnya teknologi laboratorium pengujian pangan,(3) Regulasi pemerintah tentang keamanan pangan, (4)Tumbuhnya kesadaran keamanan pangan, (5) isu-isu terkait keamanan pangan, (6) Hambatan masuk cukup tinggi, dan (7) Posisi daya tawar pemasok terhadap perusahaan cukup rendah. Ancaman terdiri dari (1) Isu-isu aktivitas laboratorium berdampak buruk terhadap lingkungan sekitar terutama masalah pencemaran lingkungan,(2) Kondisi politik saat ini kurang stabil,(3) Persaingan jasa laboratorium pengujian pangan di Indonesia cukup ketat,(4) Posisi daya tawar konsumen terhadap perusahaan tinggi.

Setelah diidentifikasi, maka dianalisis besarnya pengaruh kekuatan dan kelemahan. Hasil analisis Matriks IFE, kekuatan utama yang dimiliki M-BRIO Food Laboratory adalah dipimpin oleh pakar pangan yang sudah diakui reputasinya secara nasional dan internasional. Kekuatan tersebut merupakan diferensiasi antara M-BRIO Food Laboratory sebagai laboratorium pengujian pangan terhadap laboratorium pengujian pangan lainya. Nama besar pakar pangan (F.G. Winarno) dapat dimanfaatkan untuk meningkatkan citra perusahan dan membangun loyalitas pelanggan terhadap jasa pengujian. Caranya antara lain dengan melakukan promosi dan edukasi berupa seminar teknologi pangan untuk para akademisi dan praktisi industri pangan dan kampanye budaya keamanan pangan kepada masyarakat umum hal tersebut untuk meningkatkan citra perusahaan sebagai laboratorium pengujian pangan yang berintegritas dan berkualitas. Kekuatan kedua adalah memiliki komitmen "Akurat, cepat, dan bersahabat demi kepuasan pelanggan". Moto ini sesuai dengan kondisi pasar saat ini yang membutuhkan keakuratan dan kecepatan data didalam memenangkan persaingan. Bersahabat demi kepuasan pelanggan merupakan komitmen laboratorium untuk melayani dan memelihara hubungan dengan pelanggan. Kekuatan berikutnya adalah Laboratorium khusus pangan dengan jasa pengujian melingkupi 56 produk pangan sudah terakreditasi KAN. Akreditasi ini meningkatkan reputasi dan sertifikasi yang dikeluarkan memiliki kredibilitas yang tinggi.

Kelemahan utama yang dimiliki oleh M-BRIO Food Laboratory adalah sistem administrasi masih manual dan belum memiliki sistem secara terkomputerisasi diikuti keadaan tampilan eksterior dan interior bangunan laboratorium belum tertata dengan baik. Sebagai perusahaan jasa penampilan bukti fisik (physical evidence) perlu dikelola dengan baik karena berdampak pada kesan pelanggan. Komputerisasi menjadi bagian penting dalam citra memodernisasi teknologi. Perbaikan tampilan eksterior dan interior harus memiliki tema tampilan tertentu sehingga hal ini dapat menambah citra estetika. Kelemahan berikutnya adalah penampilan karyawan khususnya yang berhubungan dengan pelanggan belum distandarisasi. Penampilan yang khas misalnya seragam dapat memudahkan pelanggan dapat mengenali sebagai karyawan atau bukan dan memudahkan dalam berkomunikasi. Kelemahan berikutnya adalah promosi dan edukasi belum optimal. Promosi dan edukasi dapat meningkatkan penjualan jasa. Diurutan terakhir yang menjadi kelemahan perusahaan adalah karyawan yang 
berhubungan langsung dengan pelanggan belum dilatih secara khusus, yang dimaksud dengan pelatihan khusus tersebut adalah pelatihan teknik komunikasi dan pengetahuan produk perusahaan.

Berdasarkan hasil analisis matriks IFE, diperoleh total nilai tertimbang sebesar 2,732, nilai tersebut berada diatas nilai rata-rata 2,5 sehingga menurut Umar (2008) dapat disimpulkan bahwa perusahaan memiliki posisi internal yang kuat. Hasil analisis matriks IFE ini dapat dilihat pada Tabel 1.

Tabel 1. Matriks IFE M-BRIO Food Laboratory

\begin{tabular}{|c|c|c|c|}
\hline Faktor internal utama & Bobot & Peringkat & Skor bobot \\
\hline \multicolumn{4}{|l|}{ Kekuatan : } \\
\hline $\begin{array}{l}\text { Dipimpin oleh pakar pangan yang sudah diakui reputasinya secara } \\
\text { nasional dan internasional (Prof. Dr. F.G. Winarno). }\end{array}$ & 0,170 & 4,000 & 0,679 \\
\hline $\begin{array}{l}\text { Memiliki komitmen "Akurat, cepat, dan bersahabat demi kepuasan } \\
\text { pelanggan". }\end{array}$ & 0,131 & 3,667 & 0,480 \\
\hline $\begin{array}{l}\text { Laboratorium yang sudah terakreditasi KAN khusus pangan dengan } \\
\text { jasa pengujian melingkupi } 56 \text { produk pangan }\end{array}$ & 0,131 & 3,333 & 0,437 \\
\hline \multicolumn{4}{|l|}{ Kelemahan : } \\
\hline $\begin{array}{l}\text { Sistem administrasi masih manual dan belum memiliki sistem } \\
\text { secara terkomputerisasi }\end{array}$ & 0,104 & 2,000 & 0,208 \\
\hline $\begin{array}{l}\text { Karyawan yang berhubungan langsung dengan pelanggan belum } \\
\text { dilatih secara khusus }\end{array}$ & 0,131 & 2,000 & 0,262 \\
\hline $\begin{array}{l}\text { Penampilan karyawan khususnya yang berhubungan dengan } \\
\text { pelanggan belum distandarisasi }\end{array}$ & 0,107 & 2,000 & 0,214 \\
\hline $\begin{array}{l}\text { Eksterior dan interior bangunan laboratorium belum tertata } \\
\text { dengan baik. }\end{array}$ & 0,107 & 2,000 & 0,214 \\
\hline Promosi dan edukasi belum optimal. & 0,119 & 2,000 & 0,238 \\
\hline $\begin{array}{ll} & \text { Total } \\
\end{array}$ & 1,000 & & 2,732 \\
\hline
\end{tabular}

Peluang utama yang dihadapi M-BRIO Food Laboratory adalah perkembangan teknologi laboratorium pengujian pangan untuk mendukung kinerja pelayanan jasa pengujian pangan. Perusahaan dapat memanfaatkan perkembangan teknologi pengujian pangan terutama dalam meng-up date teknologi baru untuk instrument/peralatan/media pengujian. Berikutnya adalah kesadaran akan keamanan pangan mulai tumbuh dan menjadi budaya yang baru di kalangan masyarakat Indonesia secara umum. Kemudian diikuti regulasi pemerintah tentang keamanan pangan mendukung berkembangnya laboratorium pengujian pangan. Peluang berikutnya adalah isu-isu yang berkaitan dengan keamanan pangan, misalnya rekayasa genetik. Meningkatnya jumlah industri pangan, memberikan peluan yang cukup menarik walaupun tidak secara otomatis industri baru memanfaatkan jasa uji analisis pangan.

Ancaman utama yang dihadapi M-BRIO Food Laboratory secara beurutan adalah adalah posisi daya tawar konsumen terhadap perusahaan tinggi. Hal ini mempengaruhi persaingan dalam jasa laboratorium pengujian pangan di Indonesia cukup ketat. Posisi daya tawar konsumen dan persaingan yang ketat tidak dapat dihindarkan karena pengaruh bertambahnya jumlah laboratorium pengujian. Salah satu cara mengatasinya dengan memberikan pelayanan maksimal dan menampilkan diferensiasi yang dimiliki perusahaan. Kondisi politik saat ini yang kurang stabil dan kepastian hokum 
mempengaruhi keputusan investor berinvestasi dalam industri pangan nasional.Isu-isu kemungkinan aktivitas laboratorium berdampak buruk terhadap lingkungan sekitar terutama masalah pencemaran lingkungan. Proses pengolahan limbah dan edukasi terhadap keamanan jasa laboratorium pangan akan menaikan citra perusahaan.

Berdasarkan hasil analisis matriks EFE, diperoleh total nilai tertimbang sebesar 2,978, nilai tersebut berada diatas nilai rata-rata 2,5 sehingga menurut Umar (2008) dapat disimpulkan bahwa respon perusahaan tinggi dalam memanfaatkan peluang dan meminimalkan pengaruh negatif potensial dari ancaman. Hasil analisis matriks EFE ini dapat dilihat pada Tabel 2.

Tabel 2. Matriks EFE M-BRIO Food Laboratory

\begin{tabular}{|c|c|c|c|}
\hline Faktor eksternal utama & Bobot & Peringkat & Skor bobot \\
\hline \multicolumn{4}{|l|}{ Peluang : } \\
\hline Peningkatan jumlah industri pangan & 0,095 & 3,000 & 0,284 \\
\hline Perekonomian Indonesia cenderung stabil & 0,083 & 3,000 & 0,250 \\
\hline Perkembangan teknologi laboratorium pengujian pangan & 0,101 & 3,667 & 0,370 \\
\hline Regulasi pemerintah tentang keamanan pangan & 0,101 & 3,333 & 0,336 \\
\hline Tumbuhnya kesadaran dan isu keamanan pangan & 0,098 & 3,667 & 0,361 \\
\hline Hambatan masuk cukup tinggi & 0,095 & 3,333 & 0,315 \\
\hline Posisi daya tawar pemasok terhadap perusahaan cukup rendah & 0,073 & 2,667 & 0,195 \\
\hline Perekonomian Indonesia cenderung stabil. & 0,078 & 2,667 & 0,209 \\
\hline \multicolumn{4}{|l|}{ Ancaman : } \\
\hline $\begin{array}{l}\text { Isu-isu aktivitas laboratorium berdampak buruk terhadap } \\
\text { lingkungan sekitar terutama masalah pencemaran lingkungan. }\end{array}$ & 0,069 & 3,667 & 0,254 \\
\hline Kondisi politik saat ini sedang tidak stabil. & 0,062 & 3,000 & 0,185 \\
\hline $\begin{array}{l}\text { Persaingan jasa laboratorium pengujian pangan di Indonesia } \\
\text { cukup ketat }\end{array}$ & 0,074 & 2,000 & 0,149 \\
\hline Posisi daya tawar konsumen terhadap perusahaan tinggi & 0,071 & 1,000 & 0,071 \\
\hline Total & 1,000 & & 2,978 \\
\hline
\end{tabular}

\section{III.2. Formulasi Strategi Pemasaran}

Formulasi strategi menggunakan pendekatan SWOT, menghasilkan 8 alternatif strategi pemasaran (Tabel 3). Kemudian akan dipilih 4 strategi utama dengan metode perbandingan berpasangan (pairwise comparison) (Tabel 4). Hasil dari teknik bayes adalah 4 strategi utama yaitu (1) Menampilkan diferensiasi dan positioning untuk meningkatkan daya tawar dalam persaingan, (2) Melakukan promosi dan edukasi dengan menginformasikan kualitas jasa, cakupan produk ruang lingkup dan parameternya yang sudah terakreditasi KAN, kepada perusahaan pangan yang membutuhkan jasa laboratorium pengujian, (3) Melakukan pelatihan dan penataan tampilan karyawan yang berhubungan langsung dengan pelanggan, melakukan renovasi tampilan gedung dan menerapkan sistem komputerisasi dalam proses pelayanan pengujian, hal tersebut untuk memberikan pelayanan prima, (4) Melakukan kampanye budaya keamanan pangan kepada publik dengan mengangkat isu-isu keamanan pangan sebagai bentuk promosi dan edukasi dengan menampilkan pakar pangan sebagai endorser. Kemudian dibuatlah formulasi strategi yang komprehensif menggunakan AHP menggunakan 5 level. 
KEKUATAN (STRENGTHS-S)

1. Dipimpin oleh pakar pangan yang sudah diakui reputasinya secara nasional dan internasional (Prof. Dr. F.G. Winarno).

2. Memiliki komitmen "Akurat, cepat, dan bersahabat demi kepuasan pelanggan".

3. Laboratorium yang sudah terakreditasi KAN khusus pangan dengan jasa pengujian melingkupi 56 produk pangan.
KELEMAHAN(WEAKNESSES-W)

1. Sistem administrasi masih manual dan belum memiliki sistem secara terkomputerisasi.

2. Karyawan yang berhubungan langsung dengan pelanggan belum dilatih secara khusus.

3. Penampilan karyawan khususnya yang berhubungan dengan pelanggan belum distandarisasi

4. Eksterior dan interior bangunan laboratorium belum tertata dengan baik

5. Promosi dan edukasi belum optimal.

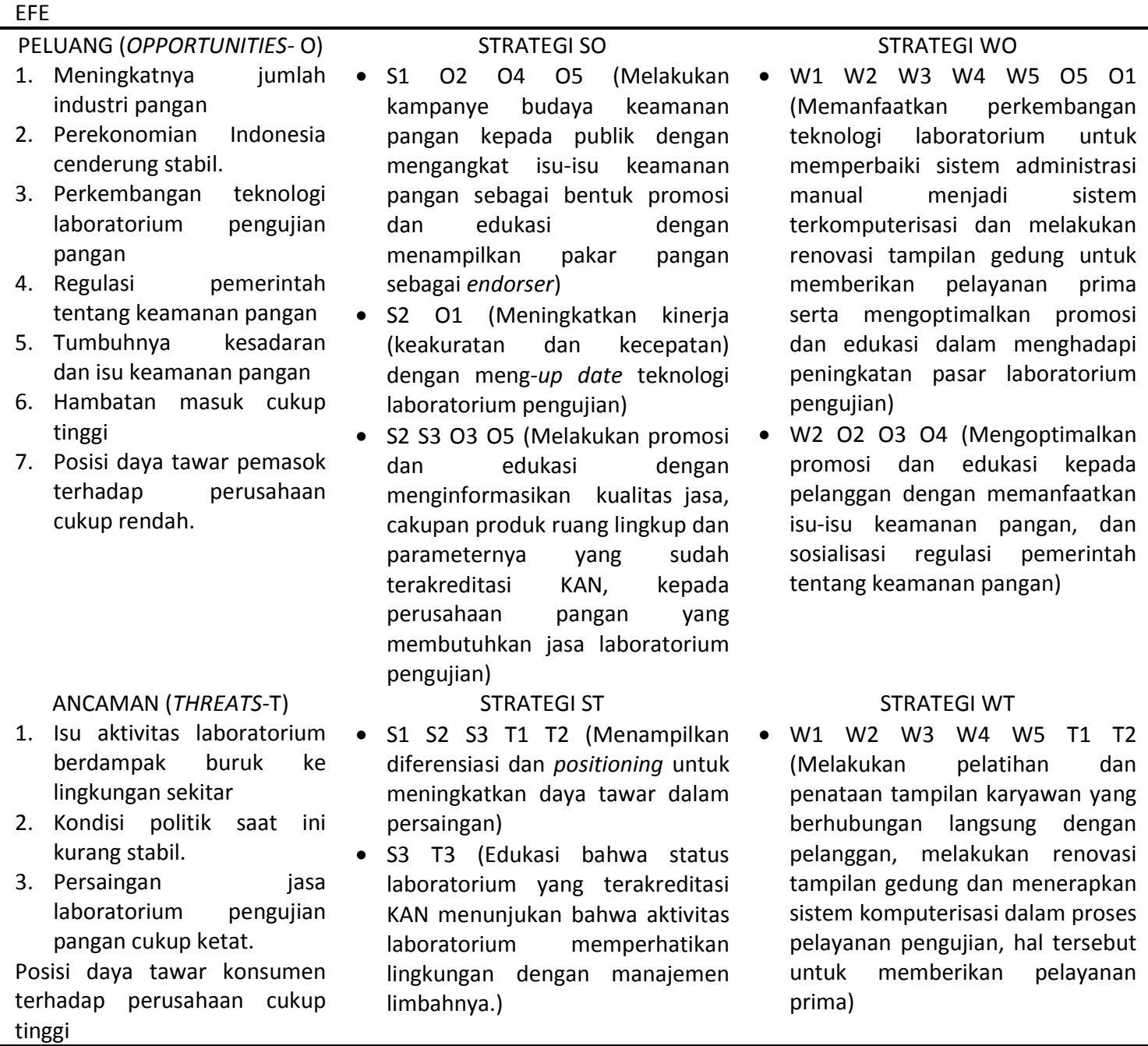


Tabel 4. Pembobotan Perbandingan Berpasangan untuk Pemilihan Strategi Pemasaran Utama

\begin{tabular}{|c|c|c|}
\hline No. & Keterangan & Bobot \\
\hline 1 & $\begin{array}{l}\text { Melakukan kampanye budaya keamanan pangan kepada publik dengan } \\
\text { mengangkat isu-isu keamanan pangan sebagai bentuk promosi dan edukasi } \\
\text { dengan menampilkan pakar pangan sebagai endorser }\end{array}$ & 0,135 \\
\hline 2 & $\begin{array}{l}\text { Melakukan peningkatan kinerja (keakuratan dan kecepatan) dengan meng-up } \\
\text { date teknologi laboratorium pengujian. }\end{array}$ & 0,088 \\
\hline 3 & $\begin{array}{l}\text { Melakukan promosi dan edukasi dengan menginformasikan kualitas jasa, cakupan } \\
\text { produk ruang lingkup dan parameternya yang sudah terakreditasi KAN, kepada } \\
\text { perusahaan pangan yang membutuhkan jasa laboratorium pengujian }\end{array}$ & 0,180 \\
\hline 4 & $\begin{array}{l}\text { Menampilkan diferensiasi dan positioning untuk meningkatkan daya tawar dalam } \\
\text { persaingan. }\end{array}$ & 0,199 \\
\hline 5 & $\begin{array}{l}\text { Edukasi bahwa status laboratorium yang terakreditasi KAN menunjukan bahwa } \\
\text { aktivitas laboratorium memperhatikan lingkungan dengan manajemen limbahnya }\end{array}$ & 0,078 \\
\hline 6 & $\begin{array}{l}\text { Memanfaatkan perkembangan teknologi laboratorium untuk memperbaiki sistem } \\
\text { administrasi yang manual menjadi sistem terkomputerisasi dan melakukan } \\
\text { renovasi tampilan gedung untuk memberikan pelayanan prima serta } \\
\text { mengoptimalkan promosi dan edukasi dalam menghadapi peningkatan pasar } \\
\text { laboratorium pengujian. }\end{array}$ & 0,081 \\
\hline 7 & $\begin{array}{l}\text { Mengoptimalkan promosi dan edukasi kepada pelanggan dengan memanfaatkan } \\
\text { isu-isu keamanan pangan, dan sosialisasi regulasi pemerintah tentang keamanan } \\
\text { pangan) }\end{array}$ & 0,096 \\
\hline 8 & $\begin{array}{l}\text { Melakukan pelatihan dan penataan tampilan karyawan yang berhubungan } \\
\text { langsung dengan pelanggan, melakukan renovasi tampilan gedung dan } \\
\text { menerapkan sistem komputerisasi dalam proses pelayanan pengujian, hal } \\
\text { tersebut untuk memberikan pelayanan prima }\end{array}$ & 0,141 \\
\hline & Rasio konsistensi (CR) & 0,017 \\
\hline
\end{tabular}

\section{III.3. Pemilihan Prioritas Strategi Pemasaran}

Pendekatan AHP yang digunakan menggunakan struktur 5 level. Level 1 (Ultimate Goal) adalah Meningkatkan efektivitas strategi pemasaran M-BRIO Food Laboratory. Level 2 ( Faktor) terdiri dari kualitas pelayanan, persaingan bisnis, budaya dan regulasi keamanan pangan serta citra perusahaan. Level 3 (aktor) terdiri dari direktur, bagian mutu dan teknis serta bagian pemasaran. Level 4 (Tujuan) terdiri dari memperluas pangsa pasar, meningkatkan penjualan dan meningkatkan loyalitas pelanggan. Level 5 (alternatif strategi) terdiri dari(1) Menampilkan diferensiasi dan positioning untuk meningkatkan daya tawar dalam persaingan, (2) Melakukan promosi dan edukasi dengan menginformasikan kualitas jasa, cakupan produk ruang lingkup dan parameternya yang sudah terakreditasi KAN, kepada perusahaan pangan yang membutuhkan jasa laboratorium pengujian, (3) Melakukan pelatihan dan penataan tampilan karyawan yang berhubungan langsung dengan pelanggan, melakukan renovasi tampilan gedung dan menerapkan sistem komputerisasi dalam proses pelayanan pengujian, hal tersebut untuk memberikan pelayanan prima, (4) Melakukan kampanye budaya keamanan pangan kepada publik dengan mengangkat isu-isu keamanan pangan sebagai bentuk promosi dan edukasi dengan menampilkan pakar pangan sebagai endorser.

Hasil akhir pengolahan AHP dengan pendekatan perbandingan berpasangan (Pairwise comparison) (Gambar 3) adalah sebagai berikut: 


\section{Faktor}

Prioritas faktor yeng mempengaruhi efektivitas pemasaran jasa laboratorium adalah kualitas pelayanan $(0,463)$, citra perusahaan $(0,241)$, persaingan bisnis $(0,201)$ dan budaya dan regulasi keamanan pangan $(0,095)$. Bobot kualitas pelayanan dua kali citra perusahaan dan persaingan bisnis. Artinya kualitas pelayanan akan mempengaruhi citra perusahaan dan membantu memenangkan persaingan bisnis. Pengaruh regulasi pangan dianggap masih kecil terhadap efektivitas pemasaran.

\section{Aktor}

Prioritas aktor adalah sebagai berikut bagian pemasaran $(0,373)$, bagian mutu dan teknis $(0,350)$, serta direktur $(0,277)$. Bagian pemasaran dan bagian mutu teknis memiliki bobot yang hampir seimbang. Koordinasi dan kerjasama du bagian tersebut akan mempengaruhi efektivitas strategi pemasaran.

\section{Tujuan}

Perusahaan memiliki tiga tujuan dalam penyusunan alternatif strategi pemasaran. Prioritasnya adalah memperluas pangsa pasar $(0,355)$, Meningkatkan penjualan $(0,336)$, dan meningkatkan loyalitas pelanggan $(0,310)$. Bobot ketiganya relatif berimbang.

\section{Alternatif Strategi}

Strategi promosi dan edukasi terkait dengan kualitas jasa M-Brio Food Laboratory kepada perusahaan pangan berpengaruh terhadap peningkatan efektifitas pemasaran mendekati 40 persen. Pengaruh berikutnya promosi dan edukasi menggunakan pakar pangan sebagai endorser terkait isu dan kemanan pangan akan meningkatkan efektivitas pemasaran sebesar 25 persen. Sedangkan pelatihan karyawan, renovasi gedung, system komputerisasi sebagai bagian dari physical evidence menaikan efektivitas pemasaran sebesar 20 persen. Selanjutnya peningkatan diferensiasi dan positioning laboratorium meningkatkan efektivitas sebesar 0,15 persen. Diferensiasi jasa laboratorium pangan relatif terbatas, salah satu yang ditawarkan adalah kemampuan perusahaan dalam melayani uji pangan baik dari segi kuantitas maupun kualitasnya. Dua prioritas untuk meningkatkan efektivitas strategi pemasaran adalah promosi dan edukasi kualitas jasa M-Brio Food Laboratory serta strategi menggunakan pakar pangan sebagai endorser. 


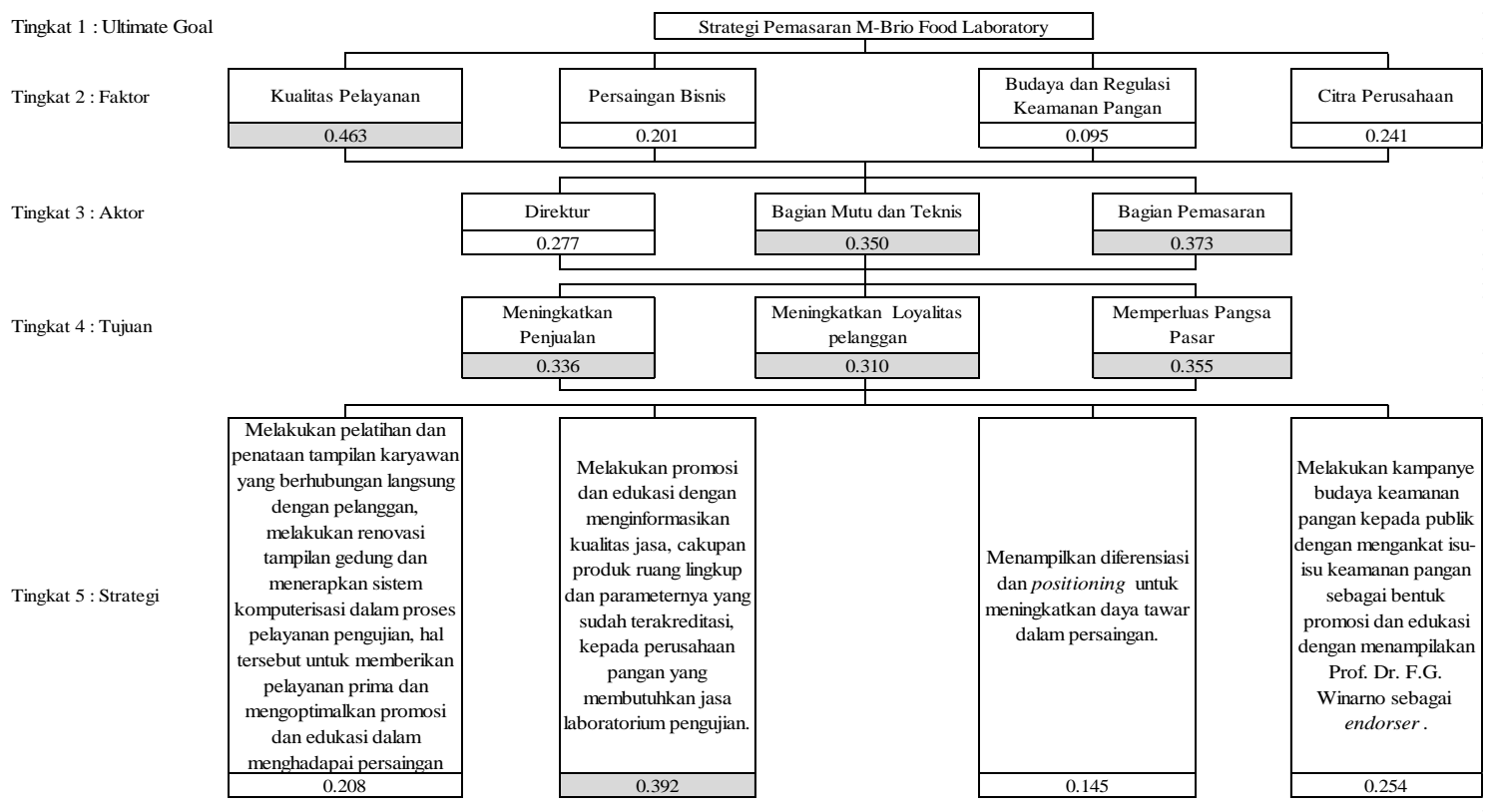

Rata-rata CR : 0,0059

Gambar 3. Struktur dan Prioritas Peningkatan Efektivitas Strategi Pemasaran M-Brio Food Laboratory

\section{Kesimpulan}

Faktor lingkungan internal yang menjadi kekuatan utama adalah dipimpin oleh pakar pangan (Prof. Dr. F.G. Winarno) terkemuka yang sudah diakui reputasinya secara nasional dan internasional. Hal ini terkonfirmasi pada prioritas ke dua strategi peningkatan efektivitas pemasaran. Faktor lingkungan internal yang menjadi kelemahan utama adalah keadaan tampilan eksterior dan interior bangunan laboratorium belum tertata dengan baik dan penampilan karyawan yang belum distandarisasi. Hal ini terkonfirmasi pada prioritas strategi ketiga. Faktor lingkungan eksternal yang dapat dimanfaatkan sebagai peluang utama adalah perkembangan teknologi laboratorium pengujian pangan. Kepakaran di bidang pangan juga harus didukung oleh perekembangan teknologi sehingga saling melengkapi. Kemampuan dan Faktor lingkungan eksternal yang menjadi ancaman utama bagi perusahaan adalah posisi daya tawar konsumen terhadap perusahaan tinggi. Hal ini terkait dengan bertambahnya alternatif jasa laboratorium uji pangan. Prioritas strategi untuk meningkatkan efektivitas pemasaran adalah adalah (1) Melakukan promosi dan edukasi dengan menginformasikan kualitas jasa, cakupan produk ruang lingkup dan parameternya yang sudah terakreditasi, kepada perusahaan pangan yang membutuhkan jasa laboratorium pengujian, (2) Melakukan kampanye budaya keamanan pangan kepada publik dengan mengangkat isu-isu keamanan pangan sebagai bentuk promosi dan edukasi untuk menaikan citra perusahaan dengan menampilkan pakar pangan Prof. Dr. F.G. Winarno sebagai salah satu endorser. 
78 | Munandar, Triatmoko, Andrianto - Analisis Strategi Pemasaran Jasa Lab

\section{Daftar Pustaka}

Badan Pusat Statistik. 2009. Penduduk Indonesia menurut Provinsi 1971, 1980, 1990, 1995, 2000 dan 2010. http://www.bps.go.id (14 Maret 2011)

2009. Jumlah Perusahaan Menurut Subsektor, 2001-2009. http://www.bps.go.id (14 Maret 2011).

Umar, Husein. 2008. Strategic Management in Action. PT Gramedia Pustaka Utama, Jakarta. 